\title{
Desenvolvimento de uma tecnologia educacional para pais e/ou cuidadores de crianças com Alergia à Proteína do Leite de Vaca (APLV)
}

\author{
Development of educational technology for children's parents and/or babysitter with Cow's \\ Milk Protein Allergy (ACMP)
}

Desarrollo de una tecnología educativa para padres y / o cuidadores de niños con Alergia a la Proteína de la Leche de Vaca (APLV)

Eva Lorena Jaques Rodrigues ${ }^{1 *}$, Rejane Maria Sales Cavalcante Mori², Sandra Maria dos Santos Figueiredo'.

\section{RESUMO}

Objetivo: Descrever o processo de produção de uma tecnologia educacional sobre Alergia à Proteína do Leite de Vaca (APLV) a partir das percepções de pais e/ou cuidadores de crianças com esta condição. Métodos: Pesquisa descritiva, quali-quantitativa, desenvolvida em uma Unidade Básica de Saúde onde funciona o Programa de alergia alimentar na região Norte. Foram avaliados 65 pais e/ou cuidadores. Foi utilizado um formulário e entrevista semiestruturada, a fim de nortear a produção da tecnologia. Os registros foram analisados por meio da análise categorial-temática. Resultados: A análise originou três categorias: Conhecer a APLV, a alimentação e seus desafios e dificuldades e o cuidado com a criança e o apoio familiar, que subsidiaram a construção da tecnologia educacional, que após sua validação, contribuirá para o cuidado à criança com APLV. A cartilha contém 49 páginas e 11 tópicos de conteúdo, com textos e imagens. Conclusão: A construção de tecnologias educacionais é uma potencial ferramenta de educação em saúde para favorecer a autonomia, promover saúde e estimular o cuidado seguro, com base nas reais necessidades dos pais e/ou cuidadores de crianças com APLV.

Palavras-chave: Tecnologia educacional, Alergia à proteína do leite de vaca, Nutrição.

\section{ABSTRACT}

Objective: To describe the production process of an educational technology on Cow's Milk Protein Allergy (ACMP) from the perceptions of parents and/or babysitter of children with this condition. Methods: Qualiitative and quantitative, descriptive research, developed in a Basic Health Unit in which the Food Allergy Program operates in the North region. Were evaluated 65 parents and / or babysitter. A form and semistructured interview were used in order to guide the production of the technology. Categorical-thematic analysis were used for records. Results: The analysis gave rise to three categories: Knowing the ACMP, food challenges and difficulties and child care and family support for building educational, which supported the construction of educational technology, which after its validation, will contribute to the care of children with ACMP. Educational booklet contains 49 pages and 11 topics with texts and images. Conclusion: The construction of educational technologies is a potential tool to health education, its promotes autonomy, health selfcare based on the real needs of childrens parents and / or baby-sitter with Cow's Milk Protein Allergy.

Keywords: Educational technology, Cow's milk protein allergy, Nutrition.

${ }_{1}$ Centro Universitário do Estado do Pará (CESUPA), Belém - PA. *E-mail: eva.jaques@hotmail.com

2 Universidade Federal do Pará (UFPA), Belém - PA. 


\section{RESUMEN}

Objetivo: Describir el proceso de producción de una tecnología educativa sobre la Alergia a la Proteína de la Leche de Vaca (AVL) a partir de las percepciones de los padres y / o cuidadores de niños con esta condición. Métodos: Investigación descriptiva, cuali-cuantitativa, desarrollada en una Unidad Básica de Salud donde opera el Programa de Alergia Alimentaria en la en la región norte. Se evaluaron 65 padres y / o cuidadores. Se utilizó un formulario y una entrevista semiestructurada para orientar la producción de la tecnología. Los registros se analizaron mediante análisis categórico-temático. Resultados: El análisis originó tres categorías: Conocer el APLV, la alimentación y sus desafíos y dificultades y el cuidado del niño y apoyo familiar, que subsidió la construcción de tecnología educativa, que luego de su validación, contribuirá al cuidado de los niños con APLV. El folleto contiene 49 páginas y 11 temas de contenido, con texto e imágenes. Conclusión: La construcción de tecnologías educativas es una potencial herramienta de educación en salud para promover la autonomía, promover la salud y fomentar un cuidado seguro, basado en las necesidades reales de los padres y / o cuidadores de niños con AVL.

Palabras clave: Tecnología educativa, Alergia a las proteínas de la leche de vaca, Nutrición.

\section{INTRODUÇÃO}

As doenças alérgicas são complexas e multifatoriais, sendo seu aparecimento associado a uma interação entre fatores ambientais e genéticos (FERNANDES SSC, et al., 2017). Para o primeiro, destaca-se a ausência do Aleitamento Materno Exclusivo (AME) nos primeiros 6 meses de vida, que tem sido relacionada a maior incidência de eczema e Alergia Alimentar (AA). Dentre os genéticos, o histórico familiar de atopia, incluindo a AA, é um fator de risco para seu aparecimento (MONTEIRO GRS, et al., 2018; SIQUEIRA SMC, et al., 2020).

Nas últimas décadas tem sido constatado um aumento das doenças alérgicas, especialmente as alimentares, devido a mudanças no estilo de vida, em que os hábitos alimentares adquiridos pela população têm uma grande interferência. Estudos mais recentes destacam a prevalência de Alergia à Proteína do Leite de Vaca (APLV) mediada por lgE em menos de 1\% em crianças (VINCENT R et al., 2021). AAPLV representa a alergia alimentar mais frequente no primeiro ano de vida, considerada um problema de saúde pública, o que gera impacto social, clínico e econômico aos pacientes e familiares, além de repercutir nas atividades do cotidiano, gerando readaptações (CORDERO R, et al., 2018).

A APLV decorre de um quadro de resposta imunológica de maneira anômala após a ingestão ou contato com determinado alimento e/ou substância, que contenha a proteína do Leite de Vaca (LV), podendo ser mediada ou não por Imunoglobulina E (IgE) ou mista (MINISTÉRIO DA SAÚDE, 2017; SILVA MVR e COELHO A, 2019). Seu diagnóstico é baseado em história clínica, exames físicos, dieta de eliminação e Teste de Provocação Oral (TPO). O diagnóstico preciso é fundamental, a fim de que se tenha o tratamento adequado (MINISTÉRIO DA SAÚDE, 2017).

O tratamento da APLV exige uma dieta de exclusão da proteína láctea ou o uso de fórmulas hipoalergênicas pela criança. Não obstante a restrição realizada ser fundamental, é importante atentar que, à longo prazo, pode haver déficits de calorias e de nutrientes, tais como de proteínas, cálcio e vitamina $D$, por isso, é importante se fazer um diagnóstico adequado, uma vez que, manter uma dieta de restrição sem necessidade pode afetar o crescimento e desenvolvimento infantil (ALVES JQN, et al., 2018; MEHTA R, et al., 2019; SOLÉ D, et al., 2018; SPOLIDORO JVN, et al., 2011).

Assim, a educação dos pais, familiares e cuidadores torna-se essencial para o sucesso do tratamento. $O$ profissional nutricionista é imprescindível no cuidado, no empoderamento das famílias no cuidado, ao realizar orientações quanto as informações corretas no que tange à escolha dos alimentos e dieta de exclusão, fazendo os ajustes adequados para suprir a demanda nutricional (PETERS RL, et al., 2015; ROCHA GS, et al., 2018).

Com a expansão das alergias alimentares, impõe-se a busca por estratégias de informação e orientação direcionadas as crianças e suas famílias. Neste contexto, as Tecnologias Educacionais (TE) são fundamentais ao intermediar a disseminação das informações ao público-alvo, advindas das necessidades do mesmo no 
que se refere à educação em saúde, servindo para mensurar o processo de ensino aprendizagem entre os facilitadores e os educandos. São instrumentos em que há a facilitação do diálogo, fortalecendo assim o vínculo entre o profissional e o usuário (NIETSCHE EA, et al., 2012; SALDAN GG, et al., 2017).

Considerando que a convivência da criança com APLV requer maior atenção por parte da família, especialmente na alimentação, por meio da leitura atenta dos rótulos industrializados a fim de identificar termos poucos conhecidos pelo consumidor que evidenciam as diferentes apresentações das proteínas do leite, acredita-se que a construção de uma TE, contendo orientações sobre tais temas e outros que envolvam o cuidado à esta criança, possa ser um instrumento terapêutico para ampliar o acesso à informação desde o diagnóstico até o tratamento, mediando o processo de ensino-aprendizagem (ALCOCER MJC, et al., 2016; SERPA FS et al., 2017).

Dessa forma, torna-se relevante uma TE voltada à demanda dessas famílias, haja vista que, eles vivenciam com medo, inquietação, dúvidas e insegurança frente ao diagnóstico, sintomas e cuidados com a alimentação (BOUSSO RS, 2008; FERREIRA S, et al., 2014). Assim, o presente estudo teve como objetivo descrever o processo de produção de uma tecnologia educacional sobre Alergia à Proteína do Leite de Vaca a partir das percepções de pais e/ou cuidadores de crianças com esta condição.

\section{MÉTODOS}

Trata-se de uma pesquisa descritiva, quali-quantitativa, de desenvolvimento metodológico, com foco na produção de uma tecnologia educacional do tipo cartilha, realizada em uma Unidade Básica de Saúde, onde funciona o Programa de alergia alimentar, na região Norte do Brasil. Os participantes da pesquisa foram 65 pais e/ou cuidadores de crianças com APLV, atendidos no Programa. A amostra foi fechada assim que foi atingido o ponto de saturação. A pesquisa foi desenvolvida seguindo todos os preceitos éticos, sendo realizada após aprovação do Comitê de Ética em Pesquisa do Centro Universitário do Estado do Pará, sob o parecer $\mathrm{n}^{\circ} 3.947 .517$.

A primeira etapa da produção da TE consistiu na seleção do conteúdo a partir de evidências disponíveis na literatura sobre APLV, a partir das seguintes bases de dados: Literatura Latino Americana e do Caribe em Ciências da Saúde (LILACS), por meio da consulta à Biblioteca Virtual em Saúde (BVS); Medical Literature Analysis and Retrieval System Online (MEDLINE), acessada por meio do portal PubMed; Scopus (Elsevier); Web of Science, utilizando as seguintes palavras chaves presentes nos Descritores em Ciências da Saúde (DeCS) e seus equivalentes no idioma inglês no Medical Subject Headings (MeSH): Alergia a alimentos e Alergia à Proteína do Leite de Vaca. Além disso, utilizou-se o Consenso Brasileiro de Alergia Alimentar, que inclui a APLV (SOLÉ D, et al., 2018). Foram incluídos trabalhos publicados no período compreendido entre 2015 e 2020.

As etapas posteriores de elaboração da TE foram: aplicação de um protocolo aos pais e/ou responsáveis; análise dos dados e construção da tecnologia educacional. A aplicação do protocolo desenvolveu-se, inicialmente, com o recrutamento de pais e/ou cuidadores de crianças com APLV. O convite foi feito em território da sala de espera do referido Programa, com explicação sobre o objetivo, riscos e benefícios da pesquisa, e para os que aceitaram participar, assinaram o Termo de Consentimento Livre e Esclarecido.

As entrevistas foram gravadas com permissão dos participantes a partir da aplicação de um formulário semiestruturado, para caracterização da amostra, levantamento das dificuldades relacionadas à alimentação, história clínica da criança e conhecimento dos pais sobre alérgenos do leite de vaca.

As gravações foram transcritas em sua integralidade para facilitar a identificação das dificuldades apresentadas e a análise realizada. A partir disso, foi possível selecionar os conteúdos que seriam abordados na cartilha, por meio da técnica de análise categorial - temática (OLIVEIRA DC, 2008). Foi realizada inicialmente leitura exaustiva e flutuante do material transcrito, com recortes dos textos em unidade de registros e agregação das informações em categorias simbólicas ou temáticas, e posterior, tratamento e interpretação dos resultados obtidos. A categorização foi definida levando em consideração os objetivos da pesquisa e o protocolo de coleta de dados com os pais e/ou cuidadores. Os demais dados coletados na pesquisa foram organizados e analisados no Software Microsoft Office Excel versão 16.30. 


\section{RESULTADOS}

Dos 65 pais e/ou cuidadores, observa-se que, 56,92\% $(n=37)$ eram do sexo feminino, com prevalência da faixa etária de 31 a 40 anos. Em relação a caracterização sociodemográfica, 43,08\% $(n=28)$ dos participantes tinham renda de 3 a 4 salários mínimos e $58,46 \%(n=38)$ ensino superior completo. No que se refere ao grau de parentesco, destaca-se a figura materna $(52,30 \%, n=34)$, o que demonstra a sobrecarga da mãe sob o cuidado à criança com APLV (Tabela 1).

Tabela 1 - Caracterização dos pais e/ou cuidadores de crianças com APLV em uma unidade de saúde.

\begin{tabular}{|c|c|c|}
\hline VARIÁVEL & $\mathbf{N}$ & $\%$ \\
\hline \multicolumn{3}{|l|}{ Sexo } \\
\hline Masculino & 28 & 43,08 \\
\hline Feminino & 37 & 56,92 \\
\hline \multicolumn{3}{|l|}{ Idade (anos) } \\
\hline $30-40$ & 13 & 20 \\
\hline $31-40$ & 32 & 49,23 \\
\hline $41-50$ & 15 & 23,08 \\
\hline $51-60$ & 5 & 7,69 \\
\hline \multicolumn{3}{|c|}{ Renda (em salários mínimos) a } \\
\hline Menor que 1 & 8 & 12,31 \\
\hline 1 a 2 & 24 & 36,92 \\
\hline 3 a 4 & 28 & 43,08 \\
\hline 5 ou mais & 5 & 7,69 \\
\hline \multicolumn{3}{|l|}{ Escolaridade } \\
\hline Fundamental incompleto & 0 & 0 \\
\hline Fundamental completo & 1 & 1,54 \\
\hline Médio incompleto & 0 & 0 \\
\hline Médio completo & 21 & 32,31 \\
\hline Superior incompleto & 5 & 7,69 \\
\hline Superior completo & 38 & 58,46 \\
\hline \multicolumn{3}{|l|}{ Grau de parentesco } \\
\hline Mãe & 34 & 52,3 \\
\hline Pai & 28 & 43,08 \\
\hline Avó & 2 & 3,08 \\
\hline Babá & 1 & 1,54 \\
\hline
\end{tabular}

Legenda: a Salário mínimo corresponde a $\mathrm{R} \$ 998,00$ no período de coleta de dados.

Fonte: Rodrigues ELJ, et al., 2021.

Para cada conjunto de respostas foram identificadas três categorias: conhecer a APLV; a alimentação e seus desafios e dificuldades; e o cuidado com a criança e o apoio familiar.

\section{Categoria 1: Conhecer a APLV}

Nesta categoria, constatou-se que os participantes se encontravam fragilizados, inseguros e cheios de dúvidas perante a situação que estavam vivenciando: a APLV. Tais sentimentos referiam-se sobretudo ao momento de início dos sintomas, diagnóstico e aos seus fatores inerentes, o que consequentemente, possibilitava diversos questionamentos sobre aspectos tais como: causa, sintomas específicos, desenvolvimento da APLV, entre outros. As respostas abaixo demonstram algumas dessas percepções.

"[...] O que ocasionou a APLV? A criança nasce ou desenvolve; o que posso ter feito de errado? [...]"

"Qual é o tempo certo de tratamento? Vai ter cura?"

"[...] Os profissionais de saúde não são bem-informados sobre o assunto. $\mathrm{Na}$ maternidade, já ofereceram Nan Supreme ${ }^{\circledR}$. Acho que o contato precoce com o leite de vaca prejudicou..." 


\section{Categoria 2: A alimentação e seus desafios e dificuldades.}

Nesta categoria, ao serem questionados quais as principais dificuldades em relação à alimentação, ficou evidente que a restrição alimentar é o principal obstáculo, contemplando aspectos como: leitura de rótulos de alimentos e consumo de alimentos em outros espaços.

A alimentação em ambientes fora de casa, como aniversários, escolas, restaurantes, demanda cuidados específicos, que a maioria dos pais relatou não ter dificuldades. A utilização de algumas estratégias mostrouse válida para contornar essa situação, como levar lanches de casa, imitar os alimentos que serão oferecidos nesses ambientes, entre outros.

Alguns pais relataram receio de incluir novos alimentos, porém referiam consultar a equipe médica para esclarecimentos. $O$ fato de não poder consumir os mesmos alimentos que as outras crianças geram por parte dos cuidadores dor, angústia e desafios em realizar a restrição. Tais afirmações enfatizam os aspectos mencionados acima.

"Encontrar produtos, rótulos claros..."

"Há poucos alimentos processados que atendem a esse público".

"Vê o irmão consumir e querer e não poder dar..."

"Tudo o que vê as outras pessoas comerem, quer; Evita comer perto dele".

"Ver ele pedir algo que contenha leite e ter que dizer não".

"Sempre levo separado, quando vou a aniversário faço as comidas no mesmo formato que contém na festa".

\section{Categoria 3: $O$ cuidado com a criança e o apoio familiar.}

Ao analisar as falas dos participantes, percebeu-se que, a maioria gostaria de conhecer melhor acerca de como lidar com APLV. Referiram-se, também, a sensibilização dos pais, da família e de todos os envolvidos no manejo com a criança, de forma a esclarecê-los sobre todos os cuidados necessários, enfatizando que a cautela não envolve apenas a exclusão de leite e derivados, e sim, outros aspectos tais como: separação de utensílios, cuidado com cosméticos, produtos de higiene, medicamentos, o que também inclui outros ambientes, que não seja sua própria casa.

Observou-se ainda, a sobrecarga sobre o cuidador principal, que em alguns casos encontravam-se fragilizados, angustiados, inseguros e cheios de dúvidas, especialmente devido à falta de apoio da família. Tais afirmações podem ser observadas nos relatos dos participantes:

"[...] a separação de tudo, como esponja. A questão dos medicamentos que também é importante; Produtos de higiene..."

"Uma experiência difícil para o ciclo familiar e o meio em que vive; Atenção constante".

"É necessária a conscientização da família, dos conhecidos, sensibilizar os pais. Não é excesso de cuidado, é real..."

"A família precisa ter conscientização sobre os alimentos, muitos não acreditam".

\section{Sobre a produção da tecnologia educacional}

A partir das questões emergentes advindas das necessidades dos pais e/ou cuidadores e das evidências científicas disponíveis na literatura, o conteúdo da TE foi construído, considerando itens como layout, ilustração, conteúdo, linguagem e motivação20.

A TE é do tipo impressa, denominada em sua versão final "Cartilha para pais e/ou cuidadores de crianças com Alergia à Proteína do Leite de Vaca (APLV)", contendo 49 páginas. No Quadro 1, observa-se a relação entre as categorias e o conteúdo da tecnologia educacional. Cada categoria temática foi descrita, 
considerando o material teórico e feita à inferência do que deveria conter na tecnologia educacional. As ilustrações foram apreciadas juntamente com o profissional designer gráfico, a fim de haver coerência entre as mesmas e sua expressividade.

Quadro 1- Relação das categorias e o conteúdo da tecnologia educacional.

\begin{tabular}{|c|c|}
\hline Categorias & Conteúdos da tecnologia educacional \\
\hline Conhecer a APLV & $\begin{array}{l}\text { 1. Entendendo a Alergia à Proteína do Leite de Vaca (APLV) } \\
\text { O que é? } \\
\text { Como posso identificar se meu filho tem APLV? } \\
\text { E essa alergia vai durar para sempre? } \\
\text { Fatores de risco } \\
\text { 2. Intolerância à lactose x Alergia à Proteína do Leite de Vaca } \\
\text { 3. Diagnóstico } \\
\text { Como diagnosticar a APLV? } \\
\text { 4. Tratamento } \\
\text { Como tratar a APLV? } \\
\text { Crianças que estão em Aleitamento Materno } \\
\text { Crianças que não estão em Aleitamento Materno }\end{array}$ \\
\hline $\begin{array}{l}\text { A alimentação e seus desafios e } \\
\text { dificuldades }\end{array}$ & $\begin{array}{l}\text { 5. Conhecendo sobre as fórmulas infantis } \\
\text { 6. Alimentação complementar } \\
\text { Aos seis meses } \\
\text { Entre sete e oito meses } \\
\text { Entre nove e onze meses } \\
\text { 7. Importância da leitura de rótulos } \\
\text { Antes de comprar produtos } \\
\text { Contaminação cruzada } \\
\text { 8. Cuidados fora de casa } \\
\text { Escolas } \\
\text { Aniversários } \\
\text { Restaurantes }\end{array}$ \\
\hline $\begin{array}{l}\text { O cuidado com a criança e o } \\
\text { apoio familiar }\end{array}$ & $\begin{array}{l}\text { 9. Outros cuidados necessários } \\
\text { 10. Apoio familiar } \\
\text { 11. Receitas culinárias }\end{array}$ \\
\hline
\end{tabular}

Fonte: Rodrigues ELJ, et al., 2021.

\section{DISCUSSÃO}

O presente trabalho descreveu o desenvolvimento de uma TE do tipo cartilha. A participação e interação dos pais e/ou cuidadores potencializaram as escolhas dos temas contidos na tecnologia. Essa interação fortalece o papel das mesmas nas demandas de cuidado, por meio da valorização de seus aspectos de vida e cria possibilidades de construção e reconstrução do saber ensinado, em que eles se tornam protagonistas da construção do instrumento (CARVALHO DS, et al., 2019).

A construção de um material educativo potencializa as orientações verbalizadas em consulta. Tal ferramenta tem impacto positivo ao gerar conhecimento, satisfação dos pacientes, melhora da aderência dos mesmos, capacidade para ajudá-los a responder as dúvidas que surjam, quando não estiver junto ao profissional de saúde (MENDONÇA SCB, et al., 2017).

As TE proporcionam interações entre o locutor (profissional de saúde), paciente e família (leitor). Sua confecção promove aquisição de conhecimento adequado à realidade, e assim, provoca mudanças de atitudes, estimulando decisões de forma autônoma a partir do entendimento de que os sujeitos, por meio de seus comportamentos, influenciam seu próprio padrão de saúde (ASSUNÇÃO APF, et al., 2017; LEITE SS, et al., 2018). 
No presente estudo, o perfil dos pais revelou predominância do sexo feminino e elevada escolaridade, corroborando aos achados de Alves JQN et al. (2018), Reis P et al. (2020) e Yonamine GH et al., (2012) envolvendo pais de crianças com alergia alimentar, o que revela que em sua maioria não há limitações econômicas e sociais. Ainda, a prevalência da figura materna no presente estudo pode associar-se a uma possível sobrecarga, o que implica em mudança da rotina familiar, excesso de responsabilidade, e consequente, aspectos emocionais negativos (ABAGARO RMA, et al., 2018; BOUSSO RS, 2008).

A partir das categorias emergentes, defronta-se com a realidade emocional das famílias, especialmente no momento do diagnóstico e de início dos sintomas, que está associado ao medo, angústia e aflição, sentimentos semelhantes aos de pais de crianças com outras doenças crônicas, o que afeta negativamente a qualidade de vida (AMÉRIGO DA, et al., 2016; LUNAA, et al., 2018).

Esse momento faz com que os pais vivenciem insegurança frente a doença e perante a ausência de credibilidade em relação à equipe de saúde, quer pela falta de capacitação, quer pelo manejo da alergia alimentar, o que implica na orientação inadequada e atribulação e desequilíbrio aos familiares, que passam a buscar informações em outras fontes (BRUM AKR, et al., 2016).

Moimaz SAS, et al. (2019) destacam que é fundamental informar aos familiares sobre a história natural da doença, seu tempo de tratamento, possível tolerância ao leite, bem como, oferecer suporte psicológico e social a essas famílias. O cuidado eficaz, o manejo, a informação, pode ser atribuído a falta de sensibilização e conhecimento dos profissionais de saúde, cujo aprimoramento é fundamental para atuação adequada no diagnóstico e tratamento da APLV (FARIA DPB, et al., 2018).

Para pais e familiares, a educação continuada com reforço da importância da exclusão completa do LV e derivados da dieta com a participação de uma equipe multiprofissional é fundamental ao sucesso do tratamento (GOMES RN, et al., 2018). A restrição alimentar foi a dificuldade citada pelos participantes, sobretudo, pelo custo, dificuldade financeira, ausência de conhecimento e de informações claras. Além disso, a monotonia alimentar é um fator limitante na alimentação, uma vez que o tratamento ao paciente com APLV é focado na exclusão da dieta de alimentos fontes de LV e derivados, visando o não reaparecimento dos sintomas e maior qualidade de vida aos portadores (FEUERHAKE T, et al., 2018).

A dificuldade na identificação de termos que signifiquem a presença de leite e/ou a leitura clara de rótulos também foi outro aspecto relatado de forma recorrente, corroborando aos achados de outros estudos (BRUM AKR, et al., 2016; REIS P, et al., 2020). Alguns pais demonstram ter receio de incluir outros alimentos. Em contrapartida, diante de dúvidas em relação a alguns produtos, referiam consultar a equipe médica, o que demonstra o vínculo com a equipe de saúde e a atuação no ensino dos cuidados de forma gradativa para aprendizagem significativa dos pais e/ou cuidadores, possibilitando o autocuidado, autoconfiança e responsabilização no tratamento.

Além disso, os pais relataram ter diferentes estratégias alimentares para os diversos espaços frequentados. A inclusão em outros ambientes, como na escola e em festas de aniversários, é fundamental para que a criança com APLV tenha direito de ser acolhida, tratada de forma igualitária, além de, contribuir para socialização (HERBERT LJ, 2017; SOLÉ D, et al., 2018).

Segundo Yonamine GH, et al (2013) o profissional nutricionista é fundamental nesse processo, por meio do ensino sobre alimentos permitidos e proibidos, leitura de rótulos, receitas e planejamento das refeições. Além disso, a disponibilização de materiais educativos para todos aqueles que mantêm contato com o paciente é necessária, o que demonstra a importância da construção de uma TE para auxiliar no suporte ao cuidado.

Em um estudo desenvolvido com nutricionistas das Unidades Básicas de Saúde, dos Núcleos Regionais de Atendimento Domiciliar e de Área Clínica, observou-se que as mesmas orientavam os pais sobre rótulos de produtos, bem como, tinham bom conhecimento em relação à APLV, baseados em protocolos científicos, o que ratifica a importância da capacitação e programas de educação continuada, a fim de um cuidado seguro (OLIVEIRA RN e HAACK A, 2017). 
No presente estudo, observou-se a fragilidade e angústia decorrente da falta de apoio, evidenciando assim a necessidade de compreensão por parte do ciclo social da família. Intitular o cuidado ao paciente com APLV como exagerado pode resultar em desconforto nas relações sociais, isolamento social, e assim, interferir na vida da família como um todo (REIS P, et al., 2020).

A educação em saúde é primordial para a construção de material educativo que possibilite informações concretas e claras para apoiar pais e/ou familiares no cuidado. A posterior validação da tecnologia educacional possibilitará a verificação da representatividade do conteúdo para o fim a que se destina, bem como, a acessibilidade e compreensão pelo público-alvo.

\section{CONCLUSÃO}

Como limitações do estudo, aponta-se a dificuldade de reunir os familiares em grupos. Além disso, destaca-se a importância do seguimento do presente estudo, bem como, de novos estudos a fim de construir outras tecnologias educacionais e inovações tecnológicas para o cuidado efetivo de crianças com APLV. O estudo identificou que os pais e ou cuidadores, em geral, não tem limitação socioeconômica. Entretanto, tem insegurança e necessidade de apoio emocional, familiar e suporte especialmente no que se refere à alimentação. A construção de uma Tecnologia Educacional, e sua posterior validação, servirá como instrumento facilitador, favorecendo o empoderamento dos pais e/ou cuidadores para que se sintam mais seguros e corresponsáveis pelo cuidado e pelas condutas a serem realizadas, podendo ser utilizado nas atividades de educação em saúde, e assim, garantir melhor qualidade de vida à criança e a sua rede de apoio.

\section{REFERÊNCIAS}

1. ABAGARO RMA, et al. Aspectos Emocionais Vivenciados pelos Pais e/ou Cuidadores de Crianças com Alergia à Proteína do Leite de Vaca. ID on line Revista de Psicologia, 2018; 12(39): 736-56.

2. ALCOCER MJC, et al. Recent advances in food allergy. Brazilian J. Food Technol., 2016; 19(0).

3. ALVES JQN, et al. Perfil nutricional e consumo dietético de crianças alérgicas à proteína do leite de vaca acompanhadas em um hospital infantil de Brasília/DF, Brasil. Com Ciências Saúde [Internet], 2018; 28(3): 402-12.

4. AMÉRIGO DA, et al. Quality of life in patients with food allergy. Clin. Mol. Allergy, 2016;14(4).

5. ASSUNÇÃO APF, et al. Práticas e Tecnologias no Cotidiano de Enfermeiras da Estratégia Saúde da Família. Revista de enfermagem UFPE online, 2017; 7(11): 6329-35.

6. BOUSSO RS. A teoria dos sistemas familiares como referencial para pesquisas com famílias que experienciam a doença e a morte. Revista Mineira de Enfermagem, 2008; 12(2):257-61.

7. BRUM AKR, et al. Gerenciamento do cuidado de enfermagem à criança com alergia a proteína do leite de vaca. Revista de enfermagem UFPE online, 2016; 10(5): 4404-7.

8. CARVALHO DS, et al. Construção de tecnologia educacional para estomizados: enfoque no cuidado da pele periestoma. Revista Bras. Enferm., 2019; 72(2): 447-54.

9. CORDERO R, et al. Actualización en manejo de Alergia a la proteína de leche de vaca: fórmulas lácteas disponibles y otros brebajes. Rev Chil Pediatr [online], 2018; 89(3): 310- 7.

10. FARIA DPB, et al. Knowledge and practice of pediatricians and nutritionists regarding treatment of cow's milk protein allergy in infants. Rev. Nutr, 2018; 31(6): 535-46.

11. FERNANDES SSC, et al. Tendência epidemiológica das prevalências de doenças alérgicas em adolescents. J. bras. pneumol., 2017; 43(5): 368-372.

12. FERREIRA S, et al. Cow \& smilk protein allergy with gastrointestinal manifestations. Birth Growth M.J., 2014; 23(2): 72-9.

13. FEUERHAKE T, et al. Caracterización clínica de pacientes chilenos con alergia alimentaria mediada por lgE. Revista chil. Pediatr., 2018; 89(4): 448-53.

14. GOMES RN, et al. Impacto psicossocial e comportamental da alergia alimentar em crianças, adolescentes e seus familiares: uma revisão. Arq. Asma Alerg. Imunol., 2018; 2(1): 95-100.

15. HERBERT LJ. Mealtime behavior among parents and their young children with food allergy. Ann. Allergy Asthma Immunol., 2017; 118(3): 345-50.

16. LEITE SS, et al. Construção e validação de Instrumento de Validação de Conteúdo Educativo em Saúde. Rev. Bras. Enferm., 2018; 71(supl. 4): 1635-41.

17. LUNA A, et al. Perception of treatment needs and use of dental services for children and adolescents with sickle cell disease. Oral Health Prev. Dent. 2018; 16(1): 51-7. 
18. MENDONÇA SCB, et al. Construction and validation of the Selfcare Assessment Instrument for patients with type 2 diabetes mellitus. Revista Lat. Am. Enfermagem, $2017 ; 25$.

19. MEHTA R. Allergy and asthma: food allergies. FP. Essent, 2018; 472: $16-9$.

20. MINISTÉRIO DA SAÚDE. Protocolo clínico e diretrizes terapêuticas alergia à proteína do leite de vaca (APLV). Brasília DF, Brasil, $2017 . \quad$ Disponível em: http://conitec.gov.br/images/Consultas/Relatorios/2017/Relatorio_PCDT_APLV_CP68_2017.pdf. Acessado em: 21 de março de 2021.

21. MOIMAZ SAS, et al. Percepção de pais de crianças alérgicas ou intolerantes alimentares em relação à doença. J Hum. Growth Dev., 2019; 29(3): 354-64.

22. MONTEIRO GRSS, et al. A introdução alimentar precoce e o risco de alergias: Revisão da literatura. Enfermería Global, 2018; (54): 485-98.

23. NIETSCHE EA, et al. Tecnologias inovadoras do cuidado em enfermagem. Rev. Enferm. UFSM, 2012; 2(1): 182-9.

24. OLIVEIRA DC. Análise de conteúdo temático-categorial: uma proposta de sistematização. Rev. enferm, UERJ, 2008; 6(4):569-76.

25. OLIVEIRA RN, HAACK A. Nutricionistas das Unidades Básicas de Saúde, dos Núcleos Regionais de Atendimento Domiciliar e da Área Clínica de uma instituição pública: conhecimentos de nutrição observados entre estes profissionais sobre o tratamento de alergia ao leite de vaca no lactente. Braspen J.,2017; 32(1):68-77.

26. PETERS RL, et al. Natural history of peanut allergy and predictors of resolution in the first 4 years of life: a populationbased assessment. J. Allergy Clin. Immunol. ,2015; 135:1257-66.

27. REIS P, et al. Repercussions of cow's milk allergy from the perspective of mothers. Rev. Rene, 2020; 21 : e42929.

28. ROCHA GS, et al A trajetória da produção de uma tecnologia educacional: cuidados domiciliares ao idoso pósneurocirurgia. Revista de enfermagem UFSM. 2018; 8(3): 605-15.

29. SALDAN GG, et al. Construção de tecnologia educativa para cuidado domiciliar após acidente vascular encefálico: relato de experiência. Revista de enfermagem UFPE online, 2017; 11(4): 1784-93.

30. SERPA FS, et al. O atendimento médico de pacientes com doenças imunoalérgicas no Brasil: reflexões e propostas para a melhoria. Arquivo Asma Alergia Imunologia, 2017; 1(4).

31. SIQUEIRA SMC, et al. A amamentação como fator de proteção para a alergia à proteína do leite de vaca na infância: o que dizem as evidências científicas?. Revista Eletrônica Acervo Científico, 2020; (49): e485.

32. SILVA MVR, COELHO A. Causas, sintomas e diagnóstico da intolerância à lactose e alergia ao leite de vaca. Revista Saúde UniToledo, 2019; 3(1): 20-31.

33. SOLÉ D, et al. Consenso Brasileiro sobre Alergia Alimentar: 2018-Parte 2-Diagnóstico, tratamento e prevenção. Documento conjunto elaborado pela Sociedade Brasileira de Pediatria e Associação Brasileira de Alergia e Imunologia. Arquivo Asma Alergia e Imunologia, 2018; 2(1): 39-82.

34. SPOLIDORO JVN, et al. Terapia nutricional no paciente com alergia ao leite de vaca. Tratado de pediatria-Projeto Diretrizes. 2011; (11).

35. VINCENT R, et al. Frequency of guideline-defined cow's milk allergy symptoms in infants: Secondary analysis of EAT trial data. Clinical \& Experimental Allergy, 2021.

36. YONAMINE GH, et al. Percepção dos familiares de pacientes com alergia ao leite de vaca em relação ao tratamento. Revista bras. crescimento desenvolvimento humano, 2013; 23(1): 58-64. 